\title{
The effectiveness of a graphical presentation in addition to a frequency format in the context of familial breast cancer risk communication: a multicenter controlled trial
}

Lidewij Henneman $^{1,4^{*}}$, Jan C Oosterwijk ${ }^{2}$, Christi J van Asperen ${ }^{3}$, Fred H Menko ${ }^{4}$, Caroline F Ockhuysen-Vermey ${ }^{1}$, Piet J Kostense ${ }^{5}$, Liesbeth Claassen ${ }^{1}$ and Daniëlle RM Timmermans ${ }^{1}$

\begin{abstract}
Background: Inadequate understanding of risk among counselees is a common problem in familial cancer clinics. It has been suggested that graphical displays can help counselees understand cancer risks and subsequent decision-making. We evaluated the effects of a graphical presentation in addition to a frequency format on counselees' understanding, psychological well-being, and preventive intentions.

Design: Multicenter controlled trial.

Setting: Three familial cancer clinics in the Netherlands.

Methods: Participants: Unaffected women with a breast cancer family history (first-time attendees). Intervention: Immediately after standard genetic counseling, an additional consultation by a trained risk counselor took place where women were presented with their lifetime breast cancer risk in frequency format (X out of 100) $(n=63)$ or frequency format plus graphical display $(10 \times 10$ human icons) $(n=91)$.

Main outcome measures: understanding of risk (risk accuracy, risk perception), psychological well-being, and intentions regarding cancer prevention. Measurements were assessed using questionnaires at baseline, 2-week and 6-month follow-up.

Results: Baseline participant characteristics did not differ between the two groups. In both groups there was an increase in women's risk accuracy from baseline to follow-up. No significant differences were found between women who received the frequency format and those who received an additional graphical display in terms of understanding, psychological well-being and intentions regarding cancer prevention. The groups did not differ in their evaluation of the process of counseling.

Conclusion: Women's personal risk estimation accuracy was generally high at baseline and the results suggest that an additional graphical display does not lead to a significant benefit in terms of increasing understanding of risk, psychological well-being and preventive intentions.

Trial registration: Current Controlled Trials ISRCTN14566836

Keywords: Breast cancer, Genetic counseling, Risk communication, Risk perception, Cancer worry, Decision-making, Graphical display
\end{abstract}

\footnotetext{
* Correspondence: I.henneman@vumc.nl

${ }^{1}$ Department of Public and Occupational Health, EMGO Institute for Health

and Care Research, VU University Medical Center, Amsterdam, The

Netherlands

${ }^{4}$ Department of Clinical Genetics, section Community Genetics, EMGO

Institute for Health and Care Research, VU University Medical Center,

Amsterdam, The Netherlands

Full list of author information is available at the end of the article
} 


\section{Background}

Risk communication in breast cancer genetic counseling aims to improve women's understanding of cancer risks in order to facilitate informed decision-making [1]. The risk communication concerns several risks, such as the risk of having a hereditary form of breast cancer, i.e. a $B R C A 1$ or $B R C A 2$ mutation. The cumulative lifetime cancer risk for carriers of a $B R C A 1 / B R C A 2$ gene-mutation is 60 to 80 percent [2,3], and these women are offered management options including periodic screening and prophylactic mastectomy. However, for most women with a breast cancer family history the condition is due to environmental factors and low or medium penetrance genes, most of which have not yet been identified. These women have cancer risks that are only slightly or moderately increased.

Several studies have shown that unaffected women with a family history of breast cancer tend to overestimate their breast cancer risk, even after genetic counseling, although underestimation also occurs $[4,5]$. Inappropriate (i.e. too high or too low) risk perceptions may lead to potentially harmful behavior, for example overscreening (or underscreening), in other words screening for breast cancer that is more (or less) intensive than that recommended based on actual risk [6,7]. Overestimation of risk may also lead to breast cancer worry and negatively affect psychological well-being [8]. It is thus important to identify strategies which will improve women's understanding of risk.

It has been shown that the way in which risks are presented may influence individuals' interpretations of risk and their subsequent decisions $[9,10]$. Risks can be displayed in various presentation formats, such as numbers or words. Protocols in breast cancer genetic counseling generally contain no guidelines for the optimal format of risk communication. Research suggests that clinical genetics professionals present risks in various ways that differ from person to person in ways that seem right to them, despite a lack of evidence to support their methods [11].

People often find it difficult to understand risks, especially when risks are presented as numerical estimates [12]. The use of (additional) graphical formats, such as population icon arrays (i.e. a matrix of icons to visually represent a population using different colors to indicate the proportion of the population that would experience the negative or positive outcome) and bar charts, is increasingly popular for risk communication [13,14]. Graphical displays may provide helpful support, in particular for persons with low numeracy skills (the ability to understand and use numbers) $[15,16]$, and are appreciated by patients $[14,17]$. Icon arrays allow the illustration of quantitative part-to-whole proportions and can counter framing effects and denominator neglect, since the size of the population is taken into account $[13,18,19]$. The impact of icon arrays on actual perceptions and understanding showed mixed results. On the one hand, researchers have shown that risks presented as icon arrays did not result in a better understanding, but did have a higher affective impact and were perceived as higher compared to numerical formats $[9,20]$. Visual formats may then be particularly useful when the primary purpose of risk communication is to increase awareness of risks. On the other hand, studies found that presenting risks in icon arrays resulted in a lower perceived risk than when presenting information in frequencies [16]. As icon arrays and other graphical presentations draw attention not only to the number of affected people but also to those who are not affected, making this information more salient [21], perceived risk may be lower than for numerical risk information [16].

Although graphical displays are suggested to enhance quantitative risk communication, empirical evidence from clinical settings is scarce and few studies have been in the form of controlled trials aimed at individuals at high cancer risk. In a prospective randomized controlled trial, Ghosh et al. [22] showed that the use of icons arrays plus bar chart improved the accuracy of risk perception in breast cancer counseling. Most studies on risk presentation formats that have been conducted are, however, descriptive or were performed in a laboratory or experimental setting with hypothetical scenarios and short-term follow-up $[16,23,24]$. To translate these results into practice, more studies are needed involving counselees making real-life decisions.

The main objective of this study was to evaluate the effect of a graphical risk communication format in addition to a frequency format in genetic breast cancer counseling with regard to the healthy counselees' understanding of risk (risk accuracy and perception of the risk), psychological well-being, and intentions regarding cancer prevention. Based on the arguments discussed previously, it was expected that graphical displays added to a frequency format were expected to lead to better understanding $[15,22]$, and to higher affective impact $[9,20,23,25]$ compared to a frequency format alone. The study was part of the BRISC (Breast cancer RIsk Communication) study, a prospective multicenter controlled trial to optimize the communication of breast cancer risks in genetic counseling among women with a family history of breast cancer. The study protocol has been published previously [26].

\section{Methods}

\section{Study design and procedure}

The BRISC study was designed as a controlled trial with repeated measures using questionnaires. For the present study, to analyze the effect of graphical presentation, two presentations of lifetime risk information to women were compared: frequency format vs. frequency format plus a graphical display of risk. For the graphical display 
of risk information, icon arrays were used. The effect of time-frame (age-related risk information) on outcome measures - also part of the BRISC study - will be considered in future analyses, given that this was a different kind of intervention where risks were not - or not only presented in a different format but also different risks were presented. More details can be found elsewhere [26].

\section{Sample}

Power calculation indicated that 60 women per condition were needed to detect a clinically relevant difference of $10-20 \%$ change in risk accuracy between the presentation formats [26]. Unaffected women with a breast cancer family history who were first-time attendees at the familial cancer clinic were included. Women were referred to the clinical genetics departments if they fulfilled the Dutch referral criteria [27]. Women were excluded if they had a personal history of breast or ovarian cancer, were under 18 years of age, had evident psychiatric illness or terminal disease, or were unable to read and write Dutch. Recruitment to participate took place between December 2005 and November 2007 in three large Dutch clinics: VU University Medical Center Amsterdam, University Medical Center Groningen, and Leiden University Medical Center.

\section{Intervention}

Immediately after a standard genetic counseling session with the clinical geneticist or genetic counselor (usual care), an additional consultation by a trained risk counselor took place in which risks were communicated in one of two ways, namely: 1) in a frequency format (e.g. "On average, 10 out of every 100 women in the Netherlands will develop breast cancer during their lifetime"); or 2) in a frequency format plus a graphical display of risk $(10 \times 10$ human figure icons) (see for example, Figure 1). Different types of information were presented: absolute lifetime breast cancer risk for an average woman (i.e. population risk); breast cancer risk for women with $B R C A 1 / B R C A 2$ mutation; the risk passing the mutated gene to children; and the women's personal breast cancer risk as based on her family history.

After the risk consultation, which lasted approximately 30 minutes, all participants received a summary brochure 
in which risks were presented in the same formats as presented during the consultation.

\section{Procedure}

The Medical Ethics Committees of the participating centers approved the protocol. Women were informed by letter that the study was about different ways of informing women about familial breast cancer but did not mention that it was about risk communication. Participants provided written informed consent before their first visit. In each of the three centers participating, five different risk formats were provided for 3-5 consecutive months per center [26]. Women were allocated to one of the conditions depending on the month they entered the study. To correct for learning effect by the risk counselors, the ranking order of each condition presented was varied between the centers. In the current study, two of the five risk conditions were compared (frequency format and frequency format plus graphical display). Participants received a questionnaire at home before their first appointment (baseline), two weeks after the risk consultation, and six months after the risk consultation.

The genetic counselor estimated the counselees' lifetime breast cancer risk as part of standard genetic counseling. Consensus was reached to standardize the content and structure of the standard genetic counseling sessions prior to the intervention by presenting the woman's breast cancer risk as risk group (i.e. 'population risk' (10\%) or one of three increased risk categories: 'slightly increased' (11-20\%), 'moderately increased' (20-30\%) or 'highly increased' (30-40\%)), using percentages when presenting risks. The risk counselor was informed about the counselees' breast cancer risk by means of a "checklist after standard counseling" that was filled out by the genetic counselor. The checklist also included information on whether the counselee or a relative had been offered DNA testing. The study was blinded, i.e. the genetic counselors did not know which group a woman was allocated to.

\section{Measures \\ Understanding of risk}

With regard to understanding of risk, women's risk accuracy and risk perception was assessed. Risk accuracy was measured with regard to two types of risks: 1) lifetime population breast cancer risk: a risk within plus or minus $10 \%$ of the communicated risk was defined as accurate, and 2) the woman's own lifetime risk of getting breast cancer as compared to the counseled risk: a risk within their estimated risk category as provided by the risk counselor was defined as accurate. For some women the risk changed during the study due to the receipt of genetic test results and in those women accuracy was based on self-reported test results at 6-month follow-up.
Risk perception was assessed using two items on a 7point rating scale: "How likely do you think it is that you will get breast cancer during your lifetime" (very unlikely (1) - very likely (7); 'Perceived likeliness'), and "Based on your feelings, how high is your lifetime risk of developing breast cancer" (very low (1) - very high (7); 'Risk as feeling').

\section{Psychological well-being}

Psychological well-being was assessed using an adapted version of the Lerman Cancer Worry Scale (CWS) (7 items, score range 7-28) [28], and the Dutch version of the 6-item version of the State scale of the Spielberger State-Trait Anxiety Inventory (STAI) (score range 6-24) [29]. The scale reliability was good with a Cronbach's alpha of .93 for the CWS and .86 for the STAI.

\section{Preventive intentions}

Overscreening was addressed by looking at preventive intentions at 6-month follow-up. Intentions with regard to "having breast screening by a physician every 6 months", and "having a screening mammography every year" were assessed on a 7-point scale (definitely not (1) to definitely (7)). This was best assessable only in the subgroup with lowest breast cancer risk (i.e. 10-20\% risk) where this type of preventive screening is not recommended according to the Dutch guidelines, and thus low preventive intentions were considered as required based on actual risk.

\section{Evaluation of counseling process}

The process of counseling as perceived by the women was evaluated using the one-dimensional Dutch version of the Perceived Personal Control questionnaire (PPC) $(\alpha=.85)[30]$.

\section{Other measures}

Socio-demographic characteristics assessed included age, level of education, marital status, number of children, parents' country of birth, religious activity, family history of breast cancer, i.e. the number of family members that have or have had breast cancer including the family relationship. At 6-month follow-up, women were asked about the results of DNA testing.

\section{Statistical analyses}

Comparisons of baseline characteristics between groups were made using chi-square tests for categorical variables and t-tests for continuous variables. $P$-values less than .05 were considered statistically significant. Characteristics that differed at baseline between presentation formats were entered as covariates in the further analyses. Logistic regression analyses were performed to assess differences in the proportion of women with accurate risk estimates (adjusted for pre-test (T0) risk accuracy) 
between frequency format vs. frequency format plus graphical display in risk accuracy at 2 weeks (T1) and 6 months (T2). Differences were reported with odds ratios (ORs) and 95\% confidence intervals (CIs). Analysis of covariance (ANCOVA) was performed to test the effects of presentation format on perceived likeliness, risk as feelings, psychological well-being, preventive intentions and evaluation of counseling, by comparing pre-test- (T0) with post-test- (T1/T2) outcome measures. Mean differences in outcomes scores between presentation formats were reported with 95\% CIs for significant differences.

\section{Results}

\section{Response}

Over a two-year period, 557 women (55\% of the eligible counselees) gave their informed consent. After consent, 110 women were excluded, mainly because they did not meet the inclusion criteria or because they cancelled the appointment for the additional risk consultation. Another 37 women were excluded after being allocated to one of the additional risk presentation formats because the data on risk estimation/category were not yet available by the closure of the study. In total, 63 women received a frequency format and 91 women received a frequency format plus graphical display. The remaining 256 women received a different format (e.g. age-related risks), and the corresponding effect of time-frame will be presented elsewhere.

Baseline questionnaires were missing for one woman in the frequency format group, and four women in the frequency format plus graphical display group; these women were excluded from the analyses, leaving 149 women in the analyses. Baseline demographic or other participant characteristics did not differ between the two groups (Table 1). Overall, $10.1 \%$ and $20.8 \%$ of the data of participants were missing at 2-week- and 6-month follow-up due to loss to follow-up, respectively. There were no differences at baseline in outcome variables between participants with missing data at follow-up and those for whom complete data were obtained.

At 6-month follow-up, 18 women in the frequency format group, and 23 women in the frequency format plus graphical display group reported that they had received DNA test results or were still waiting for their results.

Table 1 Characteristics of the study population at baseline

\begin{tabular}{|c|c|c|c|}
\hline & $\begin{array}{l}\text { Frequency format } \\
\mathrm{N}=62\end{array}$ & $\begin{array}{l}\text { Frequency format }+ \text { Graphical display } \\
\mathrm{N}=87\end{array}$ & $\begin{array}{l}\text { Differences } \\
\text { P-value }\end{array}$ \\
\hline Age, mean (sd) year, range & $40(11), 20-63$ & $41(12), 18-70$ & $.464^{\mathrm{C}}$ \\
\hline Education $^{\mathrm{a}}, \mathrm{n}(\%)$ & & & $.804^{\mathrm{d}}$ \\
\hline Low & $10(16)$ & $15(18)$ & \\
\hline Intermediate & $26(42)$ & $30(37)$ & \\
\hline High & $26(42)$ & $37(45)$ & \\
\hline Married or cohabiting, n (\%) & $46(74)$ & $68(79)$ & $.487^{d}$ \\
\hline Number of children, mean (sd) & $1.5(1.5)$ & $1.7(1.3)$ & $.432^{c}$ \\
\hline Ethnicity, n (\%) & & & $.428^{\mathrm{d}}$ \\
\hline Both parents Dutch & $55(92)$ & $77(90)$ & \\
\hline Parent(s) not Dutch (Western) & $3(5)$ & $8(9)$ & \\
\hline Parent(s) not Western & $2(3)$ & $1(1)$ & \\
\hline (Very) actively religious, $\mathrm{n}(\%)$ & $16(25)$ & $22(26)$ & $.772^{\mathrm{d}}$ \\
\hline \multicolumn{4}{|l|}{ Family history of breast cancer } \\
\hline \# 1st degree relatives affected, mean (sd) & $1.4(0.7)$ & $1.3(0.6)$ & $.706^{\mathrm{c}}$ \\
\hline \# 2nd degree relatives affected, mean (sd) & $2.1(1.1)$ & $1.9(1.0)$ & $.261^{\mathrm{c}}$ \\
\hline Women's breast cancer risk estimation ${ }^{\mathrm{b}}, \mathrm{n}(\%)$ & & & $.268^{\mathrm{d}}$ \\
\hline Not/slightly increased (10-20\%) & $25(40)$ & $35(40)$ & \\
\hline Moderately increased (20-30\%) & $21(34)$ & $28(32)$ & \\
\hline Highly increased (30-40\%) & $16(26)$ & $25(28)$ & \\
\hline
\end{tabular}

aLow: primary school, lower level of secondary school, lower vocational training. Intermediate: higher level of secondary school, intermediate vocational training. High: higher vocational training, university.

${ }^{\mathrm{b}}$ As estimated by the genetic counselor during standard genetic counseling before risk consultation. Not/slightly increased risk group included two women with population breast cancer risk in each group.

t-test.

${ }^{\mathrm{d}} \mathrm{Chi}^{2}$-test.

Sd = standard deviation. 
For 13 of these women, the risk category changed based on the results of DNA testing. In total, seven women reported that they had had a pathogenic mutation (true positive results) after DNA testing for $B R C A$ mutations (lifetime risk changed to $60-80 \%$ ), three of whom had previously been informed that they had a slightly or moderately increased risk. For five women in both the frequency format group and the frequency format plus graphical display group, the risk changed from moderately or highly increased to a population risk of $10 \%$ due to true negative test results. Five women with true negative results were already in the lowest risk group (i.e. risk estimation did not change).

\section{Understanding of risk}

In both groups there was an overall increase in the women's accuracy of risk estimation from baseline to follow-up. At 2-week- and 6-month follow-up, no difference in risk accuracy was found between women who received the frequency format and those who received the frequency format plus graphical display (Table 2). Results did not change after excluding the women for whom the risk had changed during the study due to the receipt of genetic test results. Interestingly, in both groups, 74-79\% of women already had accurate perceptions of their own breast cancer risk before standard genetic counseling. Women who received the frequency format plus graphical display had higher breast cancer risk perceptions, although not significantly higher $(\mathrm{F}(1,108)=3.17, \mathrm{p}=0.07$ for 'Perceived likeliness', and $F(1,109)=2.88, \mathrm{p}=0.08$ for 'Risk as feeling'), at 6-month follow-up compared with women who received the frequency format only (Table 3 ).

\section{Psychological well-being}

Cancer-specific worry and state anxiety decreased over time in both groups. No significant differences were found between the risk format groups with regard to women's cancer worry (CWS) and STAI scores (Table 3).

\section{Preventive intentions}

For the subgroup of women with no or slightly increased risk of breast cancer, there was no difference between the groups in behavioral intentions with regard to breast cancer screening by physical examination or yearly mammography (Table 3 ). In both groups, women were less inclined to have screening at 6-month follow-up compared to baseline (on average from 6.6 to 4.8 - difference $95 \%$ CI $[1.14 ; 2.53]$ - for physical examination, and from 6.3 to 4.4 -difference $95 \%$ CI $[1.10 ; 2.61]$ - for yearly mammography). For yearly mammography, the difference between baseline and follow-up was smaller, although not significantly, in women who also received the graphical displays $(\mathrm{F}(1,45)=3.16, \mathrm{p}=0.08)$.

\section{Evaluation of counseling process}

No significant differences were observed between scores on PPC of women in the two groups (Table 3).

\section{Discussion}

This study investigated the effect of a graphical presentation format in addition to a frequency format among healthy women with a family history of breast cancer attending genetic counseling. There was an overall increase in women's accuracy of lifetime risk estimation from baseline to follow-up. However, no significant differences were found between the group who received the frequency format compared to the group who received the frequency format with a graphical display in terms of understanding of risk, psychological well-being and preventive intentions. No differences were found in women's evaluation of the counseling process.

The BRISC study is a field study; in other words, it is a clinical trial which offers a unique opportunity to evaluate effects of different formats of communicating risks to counselees having to make real-life decisions. The study was a multicenter trial encompassing three out of nine Dutch familial cancer clinics. Women were allocated to receiving a particular risk communication format depending on the time they entered the study. Not only were the direct effects of communication assessed but also the effects at 6-month follow-up. In interpreting the results, one must, however, realize that any effect of different formats for risk communication on people's perception and decision-making is bound to be small, in

Table 2 Women's risk accuracy at baseline, 2-week and 6-month follow-up, by intervention group

\begin{tabular}{|c|c|c|c|c|c|c|c|c|}
\hline & \multicolumn{3}{|c|}{ Frequency format } & \multicolumn{3}{|c|}{ Frequency format + Graphical display } & \multirow{2}{*}{\multicolumn{2}{|c|}{$\begin{array}{l}\text { OR [95\% Cl] } \\
\text { Adjusted for differences } \\
\text { in baseline characteristics }\end{array}$}} \\
\hline & \multirow{2}{*}{$\begin{array}{l}\text { baseline } \\
\% \\
N=62\end{array}$} & \multirow{2}{*}{$\begin{array}{l}\text { 2-week } \\
\% \\
\mathrm{~N}=55\end{array}$} & \multirow{2}{*}{$\begin{array}{l}\text { 6-month } \\
\% \\
N=47\end{array}$} & \multirow{2}{*}{$\begin{array}{l}\text { baseline } \\
\% \\
N=87\end{array}$} & \multirow{2}{*}{$\begin{array}{l}\text { 2-week } \\
\% \\
N=79\end{array}$} & \multirow{2}{*}{$\begin{array}{l}\text { 6-month } \\
\% \\
\mathrm{~N}=71\end{array}$} & & \\
\hline & & & & & & & 2-week & 6-month \\
\hline \multicolumn{9}{|l|}{ Understanding of risk } \\
\hline \multicolumn{9}{|l|}{ Risk accuracy (\% correct) } \\
\hline Population breast cancer risk & 32 & 80 & 55 & 37 & 87 & 71 & $1.44[.53 ; 3.92]$ & $1.85[.85 ; 4.06]$ \\
\hline Women's own breast cancer risk & 79 & 88 & 89 & 74 & 90 & 83 & $1.33[.41 ; 4.37]$ & $.56[.18 ; 1.72]$ \\
\hline
\end{tabular}

$\mathrm{OR}=$ Odds ratio for frequency format + graphical display vs. frequency format only; $\mathrm{Cl}=$ confidence interval. 
Table 3 Women's understanding of risk, psychological well-being, preventive intentions and evaluation at baseline, 2-week and 6-month follow-up, by intervention group

\begin{tabular}{|c|c|c|c|c|c|c|c|c|}
\hline & \multicolumn{3}{|c|}{ Frequency format $^{a}$} & \multicolumn{3}{|c|}{ Frequency format + Graphical display } & \multirow{2}{*}{\multicolumn{2}{|c|}{$\begin{array}{l}\text { Mean difference }[95 \% \mathrm{Cl}] \\
\text { Adjusted for differences } \\
\text { in baseline characteristics }\end{array}$}} \\
\hline & \multirow{2}{*}{$\begin{array}{l}\text { baseline } \\
\text { mean (sd) } \\
N=62\end{array}$} & \multirow{2}{*}{$\begin{array}{l}\begin{array}{l}\text { 2-week } \\
\text { mean (sd) } \\
\mathrm{N}=55\end{array} \\
\end{array}$} & \multirow{2}{*}{$\begin{array}{l}\text { 6-month } \\
\text { mean (sd) } \\
\mathrm{N}=47\end{array}$} & \multirow{2}{*}{$\begin{array}{l}\text { baseline } \\
\text { mean (sd) } \\
\mathrm{N}=87\end{array}$} & \multirow{2}{*}{$\begin{array}{l}\text { 2-week } \\
\text { mean (sd) } \\
\mathrm{N}=79\end{array}$} & \multirow{2}{*}{$\begin{array}{l}\text { 6-month } \\
\text { mean (sd) } \\
\mathrm{N}=71\end{array}$} & & \\
\hline & & & & & & & 2-week & 6-month \\
\hline \multicolumn{9}{|l|}{ Understanding of risk } \\
\hline Perceived likeliness (scale 1-7) & $4.8(1.1)$ & $4.2(1.5)$ & $3.9(1.4)$ & $4.8(1.3)$ & $4.3(1.3)$ & $4.3(1.5)$ & $.11[-.42 ; .64]$ & $.46[-.05 ; .97]$ \\
\hline Risk as feeling (scale 1-7) & $4.9(1.6)$ & $4.4(1.7)$ & $4.2(1.7)$ & $4.8(1.6)$ & $4.4(1.7)$ & $4.7(1.6)$ & $.05[-.48 ; .57]$ & $.50[-.08 ; 1.08]$ \\
\hline \multicolumn{9}{|l|}{ Psychological well-being } \\
\hline CWS (scale 7-28) & $12.3(3.8)$ & $11.9(2.9$ & $11.6(3.4)$ & $13.2(3.6)$ & $12.7(3.2)$ & $12.2(3.3)$ & $.07[-.66 ; 81]$ & $.32[-.97 ; 1.02]$ \\
\hline STAI (scale 6-24) & $10.0(2.9)$ & $9.5(3.5)$ & $9.3(3.3)$ & $10.7(3.4)$ & $10.2(3.4)$ & $9.6(3.4)$ & $.39[-.59 ; 1.37]$ & $.08[-1.02 ; .85]$ \\
\hline \multicolumn{9}{|l|}{ Preventive intentions ${ }^{b}$} \\
\hline $\begin{array}{l}\text { Breast screening by physician } \\
\text { (scale } 1-7 \text { ) }\end{array}$ & $6.5(0.9)$ & & $5.0(2.4)$ & $6.6(0.8)$ & & $4.7(2.7)$ & & $-.24[-1.69 ; 1.20]$ \\
\hline Yearly mammography (scale 1-7) & $6.3(1.2)$ & & $3.7(2.8)$ & $6.3(1.2)$ & & $4.9(2.6)$ & & $1.33[-.18 ; 2.85]$ \\
\hline \multicolumn{9}{|l|}{ Evaluation } \\
\hline $\begin{array}{l}\text { Perceived personal control } \\
\text { (scale 9-27) }\end{array}$ & $19.1(4.2)$ & $20.1(4.2)$ & $19.4(4.0)$ & $18.3(4.4)$ & $19.9(4.0)$ & $19.9(4.2)$ & $-.07[-1.35 ; 1.32]$ & $.65[-.85 ; 2.15]$ \\
\hline
\end{tabular}

anadjusted means and standard deviations (sd) are presented.

${ }^{b}$ Data only presented for women in the lowest risk category (10-20\%) at 6-month follow-up: $n=19$ (frequency format) and $n=29$ (frequency format and graphical display).

$\mathrm{Cl}=$ confidence interval.

particular since this study involved a standard counseling session before the risk communication consultation (intervention) where the risks already had been discussed. Moreover, the sample was powered to detect a difference in risk accuracy. However, within each condition women were already quite accurate with regard to their own risk estimate leaving little room for improvement in both groups. Furthermore, for some women in both groups the risk status had changed as a result of genetic testing, as one would expect to happen in real life. In these cases, risk was based on the self-reported test results, which might differ from their actual risk status. For logistical reasons, actual test results were not recorded in this study. Moreover, the study measured women's intentions to preventive behavior, and it is well known that there is often a discrepancy between intentions and actual behavior. Some caution should be taken in generalizing the results to all women with familial cancer since women with low education and women of ethnic minority groups were underrepresented. It is well known that in general women who come to the familial cancer clinics are higher educated women and therefore not representative for the whole population. Also, at 6 months, loss to follow-up was $25 \%$ and $22 \%$ of the women in the frequency format and frequency format plus graphical display group, respectively. To study differences in preventive intentions, as we intended to do for a small subgroup of women with low risk, a larger sample is probably needed.
This study showed no significant effects of an additional graphical display to a frequency format on the outcome measures. However, at 6-month follow-up, women who received the additional graphical display had higher risk perceptions, although not significantly higher, and, for women in the lowest risk category, higher intentions to have yearly mammography compared to women who received the frequency format only. There is mixed evidence regarding graphical displays improving understanding or aiding decision-making [31]. Earlier studies did not find an effect of population array displays on improved understanding, but did have a higher affective impact, with the effect being perceived as larger compared to numerical formats $[9,20]$. Numbers are shown to communicate more detailed or precise informational aspects, whereas graphical displays have sometimes been shown to better communicate the most significant message or gist (general impression) [15,32]. It may be that in the present study, the frequency format represented as additional graphical information did not add to the accuracy of the understanding of the information already presented as numerical frequencies. Hence an individual who understands the frequency format may not need the additional graphic display to comprehend the information.

In this study, only icon arrays were evaluated, while other graphical displays such as bar charts may also be used. Waters et al. [24], for example, demonstrated that bar graphs led to better understanding than numerical risk information only. Bar charts may be particularly 
helpful when comparing multiple risks [32], and are, for example, available to support shared decision-making for women with high breast cancer risks [33]. Ghosh et al. [22] found that breast cancer risk communication using a graphical display (icons) accompanied by a bar graph can improve short-term accuracy among women who perceived very high risks ( $>50 \%)$. The question remains as to whether adding a graphical display may have adverse effects since it increases the quantity of information and possibly also the overestimation of risks.

It has been shown that inadequate perception of risk may lead to screening that is not consistent with the recommendations for their actual risk category [34]. The present study showed that intentions regarding screening among women with a low to slightly increased breast cancer risk actually decreased after counseling, and thus were more in accordance with the guidelines, suggesting that these women understood the consequences of their risk more correctly after counseling.

Although risks are generally assumed to be important for decision-making, the results suggest that the way in which risks are presented does not influence women's intentions, either because the presentation format has no effect on their understanding of the risks, or because women do not consider risks important for their decisions. For counselees, the risk level, in whatever form it is presented, may be less relevant compared to other factors, e.g. emotions such as worry and pre-existing beliefs [34]. It has also been argued that personal characteristics such as cognitive ability and the ability to understand graphs (graph literacy) may influence the perception and comprehension of risks [19,35-37]. Future studies need to consider who might or might not benefit from different formats of health risks communication, and whether certain formats may thereby overcome differences in cognitive ability.

Up till now, in most studies, the majority of unaffected women with a family history of breast cancer overestimated their breast cancer risk $[4,5]$. In contrast, our study showed that nearly eighty percent of women in both groups accurately reported their breast cancer risk before standard genetic counseling, leaving little room for improvement and comparison between groups. The women seemed thus better informed about their own risk than women in other studies. One explanation may be the increasing attention for (hereditary) breast cancer in the media in recent years and the fact that more women and their families ask to be referred for counseling, suggesting a higher current awareness of familial risks. Nevertheless, some misunderstanding of risk prevailed, for example only one third of women could accurately report the population risk before counseling. An alternative explanation is the methodological differences between studies, caused by a wide range of risk accuracy measures [38]. A systematic review of the impact of genetic counseling on risk perception accuracy has shown that accurate risk perception can be defined in many different ways [4]. The authors of this review argued that risk perception accuracy should be defined as correctly counseled risk (i.e. in accordance with the clinician's estimate). In the presented study, we have chosen to define accuracy as falling within the correct risk category, as this was how women's own risk was actually counseled during standard genetic counseling.

\section{Conclusion}

The results of this controlled trial suggest that a graphical presentation in addition to a frequency format has no effect on understanding of risks, psychological impact and screening intentions. Further research is needed to establish whether this is indeed the case.

Competing interests

The authors declare that they have no competing interests.

\section{Authors' contribution}

$\mathrm{LH}, J \mathrm{O}, \mathrm{CVA}, \mathrm{FM}$ and DT designed the study. CO coordinated the data collection. LC and PK planned the analysis. LC performed the statistical analysis. LH wrote the first draft of the manuscript. All authors contributed to the final manuscript and have approved it.

\section{Acknowledgments}

This study was funded by the Dutch Cancer Society (grant VU 2004-2994). We thank Ineke Bakker, Nandy Hofland, Monica Legdeur and Vera Giebels, and all clinical geneticists and genetic counselors for the huge effort they put into the study. Special thanks are due to all women who took the time to complete the questionnaires.

\section{Author details}

${ }^{1}$ Department of Public and Occupational Health, EMGO Institute for Health and Care Research, VU University Medical Center, Amsterdam, The Netherlands. ${ }^{2}$ Department of Genetics, University of Groningen, University Medical Center Groningen, Groningen, The Netherlands. ${ }^{3}$ Department of Clinical Genetics, Leiden University Medical Center, Leiden, The Netherlands. ${ }^{4}$ Department of Clinical Genetics, section Community Genetics, EMGO Institute for Health and Care Research, VU University Medical Center, Amsterdam, The Netherlands. ${ }^{5}$ Department of Epidemiology and Biostatistics, VU University Medical Center, Amsterdam, The Netherlands.

Received: 17 October 2012 Accepted: 22 April 2013

Published: 29 April 2013

\section{References}

1. Julian-Reynier C, Welkenhuysen M, Hagoel L, Decruyenaere M, Hopwood P: Risk communication strategies: state of the art and effectiveness in the context of cancer genetic services. Eur J Hum Genet 2003, 11:725-736.

2. Evans DG, Shenton A, Woodward E, Lalloo F, Howell A, Maher ER: Penetrance estimates for BRCA1 and BRCA2 based on genetic testing in a Clinical Cancer Genetics service setting: risks of breast/ovarian cancer quoted should reflect the cancer burden in the family. BMC Cancer 2008, 8:155.

3. Chen SN, Parmigiani G: Meta-analysis of BRCA1 and BRCA2 penetrance. J Clin Oncol 2007, 25:1329-1333.

4. Smerecnik CM, Mesters I, Verweij E, De Vries NK, De VH: A systematic review of the impact of genetic counseling on risk perception accuracy. J Genet Couns 2009, 18:217-228.

5. Butow PN, Lobb EA, Meiser B, Barratt A, Tucker KM: Psychological outcomes and risk perception after genetic testing and counselling in breast cancer: a systematic review. Med J Aust 2003, 178:77-81.

6. Dawson SJ, Price MA, Jenkins MA, McKinley JM, Butow PN, McLachlan SA, et al: Cancer risk management practices of noncarriers within BRCA1/2 
mutation positive families in the Kathleen Cuningham Foundation Consortium for Research into Familial Breast Cancer. J Clin Oncol 2008, 26:225-232.

7. Katapodi MC, Dodd MJ, Lee KA, Facione NC: Underestimation of breast cancer risk: influence on screening behavior. Oncol Nurs Forum 2009, 36:306-314.

8. Watson M, Lloyd S, Davidson J, Meyer L, Eeles R, Ebbs S, et al: The impact of genetic counselling on risk perception and mental health in women with a family history of breast cancer. Br J Cancer 1999, 79:868-874.

9. Timmermans D, Molewijk B, Stiggelbout A, Kievit J: Different formats for communicating surgical risks to patients and the effect on choice of treatment. Patient Educ Couns 2004, 54:255-263.

10. Marteau TM, Saidi G, Goodburn S, Lawton J, Michie S, Bobrow M: Numbers or words? A randomized controlled trial of presenting screen negative results to pregnant women. Prenat Diagn 2000, 20:714-718.

11. Henneman L, Marteau TM, Timmermans D: Clinical geneticists' and genetic counselors' views on the communication of genetic risks: a qualitative study. Patient Educ Couns 2008, 73:42-49.

12. Gigerenzer G, Gaissmaier W, Kurz-Milcke EL, Schwartz LM, Woloshin S: Helping doctors and patients make sense of health statistics. Psychol Sci Public Interest 2007, 8:53-96.

13. Spiegelhalter $D$, Pearson $M$, Short $I$ : Visualizing uncertainty about the future. Science 2011, 333:1393-1400.

14. Lipkus IM, Hollands JG: The visual communication of risk. J Natl Cancer Inst Monogr 1999, 25:149-163.

15. Hawley ST, Zikmund-Fisher B, Ubel P, Jancovic A, Lucas T, Fagerlin A: The impact of the format of graphical presentation on health-related knowledge and treatment choices. Patient Educ Couns 2008, 73:448-455.

16. Galesic M, Garcia-Retamero R, Gigerenzer G: Using icon arrays to communicate medical risks: overcoming low numeracy. Health Psychol 2009, 28:210-216.

17. Goodyear-Smith F, Kenealy T, Wells S, Arroll B, Horsburgh M: Patients' preferences for ways to communicate benefits of cardiovascular medication. Ann Fam Med 2011, 9:121-127.

18. Garcia-Retamero R, Galesic M: Who profits from visual aids: overcoming challenges in people's understanding of risks. Soc Sci Med 2010, 70:1019-1025.

19. Gaissmaier W, Wegwarth O, Skopec D, Muller AS, Broschinski S, Politi MC: Numbers can be worth a thousand pictures: Individual differences in understanding graphical and numerical representations of health-related information. Health Psychol 2012, 31:286-296.

20. Timmermans DR, Ockhuysen-Vermey CF, Henneman L: Presenting health risk information in different formats: the effect on participants' cognitive and emotional evaluation and decisions. Patient Educ Couns 2008, 73:443-447.

21. Stone ER, Sieck WR, Bull BE, Yates JF, Parks SC, Rus CJ: Foreground: background salience: Explaining the effects of graphical displays on risk avoidance. Organ Behav Hum Decis Process 2003, 90:19-36.

22. Ghosh K, Crawford BJ, Pruthi S, Williams Cl, Neal L, Sandhu NP, et al: Frequency format diagram and probability chart for breast cancer risk communication: a prospective, randomized trial. BMC Womens Health 2008, 8:18

23. Chua HF, Yates JF, Shah P: Risk avoidance: graphs versus numbers. Mem Cognit 2006, 34:399-410

24. Waters EA, Weinstein ND, Colditz GA, Emmons K: Formats for improving risk communication in medical tradeoff decisions. J Health Commun 2006 11:167-182

25. Siegrist $M$, Orlow $P$, Keller $C$ : The effect of graphical and numerical presentation of hypothetical prenatal diagnosis results on risk perception. Med Decis Making 2008, 28:567-574

26. Ockhuysen-Vermey CF, Henneman L, van Asperen CJ, Oosterwijk JC, Menko $\mathrm{FH}$, Timmermans DR: Design of the BRISC study: a multicentre controlled clinical trial to optimize the communication of breast cancer risks in genetic counselling. BMC Cancer 2008, 8:283.

27. STOET: Erfelijke tumoren: Richtlijnen voor diagnostiek en preventie. Stichting Opsporing Erfelijke Tumoren en de Vereniging Klinische Genetica Nederland, Werkgroep Klinische Oncogenetica; 2005.

28. Lerman C, Trock B, Rimer BK, Jepson C, Brody D, Boyce A: Psychological Side-Effects of Breast-Cancer Screening. Health Psychol 1991, 10:259-267.

29. van der Bij AK, de Weerd S, Cikot RJ, Steegers EA, Braspenning JC: Validation of the dutch short form of the state scale of the Spielberger
State-Trait Anxiety Inventory: considerations for usage in screening outcomes. Community Genet 2003, 6:84-87.

30. Smets EM, Pieterse AH, Aalfs CM, Ausems MG, van Dulmen AM: The perceived personal control (PPC) questionnaire as an outcome of genetic counseling: reliability and validity of the instrument. Am J Med Genet A 2006, 140:843-850.

31. Timmermans DR, Oudhoff JO: Different formats for the communication of risks: verbal, numerical and graphical formats. In Wiley encyclopedia of operations research and management science. Edited by Cochran JJ. John Wiley \& Sons, Inc; 2010.

32. Feldman-Stewart D, Kocovski N, McConnell BA, Brundage MD, Mackillop WJ: Perception of quantitative information for treatment decisions. Med Decis Making 2000, 20:228-238.

33. Kurian AW, Munoz DF, Rust $P$, Schackmann EA, Smith $M$, Clarke $L$, et al: Online tool to guide decisions for BRCA1/2 mutation carriers. J Clin Oncol 2012, 30:497-506.

34. Sivell S, Elwyn G, Gaff CL, Clarke AJ, Iredale R, Shaw C, et al: How risk is perceived, constructed and interpreted by clients in clinical genetics, and the effects on decision making: systematic review. J Genet Couns 2008, 17:30-63.

35. Rees G, Fry A, Cull A: A family history of breast cancer: women's experiences from a theoretical perspective. Soc Sci Med 2001, 52:1433-1440

36. Reyna VF, Nelson WL, Han PK, Dieckmann NF: How numeracy influences risk comprehension and medical decision making. Psychol Bull 2009, 135:943-973.

37. Brown SM, Culver JO, Osann KE, MacDonald DJ, Sand S, Thornton AA, et al: Health literacy, numeracy, and interpretation of graphical breast cancer risk estimates. Patient Educ Couns 2011, 83:92-98.

38. Hopwood P, Howell A, Lalloo F, Evans G: Do women understand the odds? Risk perceptions and recall of risk information in women with a family history of breast cancer. Community Genet 2003, 6:214-223.

doi:10.1186/1472-6947-13-55

Cite this article as: Henneman et al:: The effectiveness of a graphical presentation in addition to a frequency format in the context of familial breast cancer risk communication: a multicenter controlled trial. BMC Medical Informatics and Decision Making 2013 13:55.

\section{Submit your next manuscript to BioMed Central and take full advantage of:}

- Convenient online submission

- Thorough peer review

- No space constraints or color figure charges

- Immediate publication on acceptance

- Inclusion in PubMed, CAS, Scopus and Google Scholar

- Research which is freely available for redistribution 